\title{
Lipoxygenase products in inflammatory synovial fluids and other exudates
}

\author{
Patrick B Costello, ${ }^{*}$ Alan N Baer, Floyd A Green
}

\begin{abstract}
Forty six synovial fluid samples from 42 patients with inflammatory joint disease were analysed by reversed phase high performance liquid chromatography to determine 5-lipoxygenase products, specifically dihydroxyeicosatetraenoic acids (diHETEs). Twenty eight per cent of the fluids which were assayed had one or more products of 5-lipoxygenase activation. Seven fluids contained leukotriene $B_{4}(0 \cdot 1-28.1 \mathrm{ng} / \mathrm{ml})$; three fluids had low concentrations of 20 carboxy/hydroxy-leukotriene $B_{4}(0.01-0.05 \mathrm{ng} / \mathrm{ml})$; three samples had leukotriene $B_{4}$ isomers $(1.5-2.4 \mathrm{ng} / \mathrm{ml})$; and four fluids contained 5,15-diHETE (2.3-16.4 $\mathrm{ng} / \mathrm{ml})$. There was a poor correlation between synovial fluid white blood cell counts and evidence of 5-lipoxygenase activation. Several fluids contained unidentified compounds with spectra similar in shape to that of trienes, but the $\lambda_{\max }$ values of these unidentified compounds were different from those of known leukotrienes. A septic peritoneal exudate and a septic pleural fluid had concentrations of leukotriene $B_{4}$ and leukotriene $B_{4}$ isomers and metabolites in a range similar to those found in synovial fluids.
\end{abstract}

(Ann Rheum Dis 1992; 51: 1215-1218)

Leukotrienes are 5-lipoxygenase products of arachidonic acid which are thought to be important mediators of the human inflammatory process. ${ }^{12}$ The studies reported here were undertaken to measure the type and concentrations of 5-lipoxygenase products and metabolites in joint effusions from patients with a variety of inflammatory joint diseases. Joint fluids were processed to optimise the recovery of total in vivo 5-lipoxygenase products present at the time of aspiration so that correlation with other parameters of inflammation could be made. In vivo leukotriene production in synovial fluids was compared with that in a limited number of exudates from the peritoneal and pleural cavities.

\section{Materials and methods}

Synovial fluid aspirates were obtained for routine diagnostic tests from 42 patients with inflammatory joint disease (rheumatoid arthritis, 16 patients; gout, 11 patients; pseudogout, two patients, septic arthritis, six patients; undiagnosed synovitis, seven patients) and the excess was flash frozen within 30 minutes and then lyophilised. In handling the peritoneal and pleural fluids, the cellular content was separated from the effusion before freezing. This separation was not performed for the synovial fluids, but the total intra- and extracellular dihydroxyeicosatetraenoic acid (diHETE) concentration was measured. Lyophilised samples or cells were then extracted with $25-50 \mathrm{ml}$ of $75 \%$ ethanol and vortex mixed for five minutes. Prostaglandin $B_{2}$ (Sigma Chemical, St Louis, MO, USA) was added as an internal standard (five nanomoles in a volume of $100 \mu \mathrm{l}$ ). In some instances the samples were acidified with formate buffer in a volume equal to $10 \%$ of the aqueous phase. After centrifugation at $1500 \mathrm{~g}$ for 10 minutes, the supernatants were rotary evaporated and the residue was transferred in methanol and ultimately reconstituted in the mobile phase for reversed phase high performance liquid chromatography (HPLC). The mean (SEM) recovery of the internal standard with this extraction technique was $58(4) \%$.

The mobile phase for determination of leukotriene $\mathrm{B}_{4}$ consisted of water/acetonitrile/ methanol/acetic acid, 45:37:18:1 (pH 5.6 with sodium hydroxide) and that for the determination of 20-hydroxy and 20-carboxy-leukotriene $\mathrm{B}_{4}$ consisted of methanol/water/acetic acid, 50:50:0 1. The reversed phase HPLC was performed isocratically using a Hewlett-Packard 1090 liquid chromatograph (Hewlett-Packard, Palo Alto, CA, USA), Hewlett-Packard ODSHypersil columns $(20 \mathrm{~cm} \times 4.6 \mathrm{~mm})$ and a flow rate of $0.4 \mathrm{ml} / \mathrm{min}$. This liquid chromograph is equipped with a diode array spectrophotometer and a computer for on-line display and storage of ultraviolet spectra, and thus an analysis of the purity of each peak and precise measurement of the $\lambda_{\max }$ of each peak can be performed after each chromatographic run. Authentic standards for leukotriene $B_{4}, 20$-hydroxy-leukotriene $B_{4}$, and 20-carboxy-leukotriene $B_{4}$ were obtained from BioMol Research Labs (Plymouth Meeting, PA, USA). The retention times of these standards were determined at the start of each HPLC run and were highly reproducible within and between HPLC assay sessions. The HPLC analyses were routinely monitored at wavelengths of $270 \mathrm{~nm}$ (for the detection of leukotriene $\mathrm{B}_{4}$ and its metabolites) and $245 \mathrm{~nm}$ (for the detection of diHETEs). In some instances HPLC in a second system was also performed. Each 5-lipoxygenase product was identified on the basis of its characteristic ultraviolet spectrum and retention time (compared with authentic standards) on one or more HPLC systems. This instrument is capable of detecting and defining the ultraviolet spectrum of leukotriene $B_{4}$ in amounts of $10 \mathrm{ng}$ or higher. The detection range of this instrument $(0-3$ absorbance units) is linear. In the figures the ordinate is expressed in milliabsorption units (mAU). Software programs 
Table 1 Lipoxygenase products in synovial effusions

\begin{tabular}{|c|c|c|c|c|c|c|c|}
\hline \multirow{2}{*}{$\begin{array}{l}\text { Patient } \\
\text { No }\end{array}$} & \multirow[t]{2}{*}{ Diagnosis* } & \multicolumn{2}{|c|}{ Symovial fluid } & \multicolumn{3}{|c|}{ Leukotriene (ng/ml) } & \multirow{2}{*}{$\begin{array}{l}\text { 5,15-diHETE } \\
(\mathrm{ng} / \mathrm{ml})\end{array}$} \\
\hline & & $\begin{array}{l}\text { Volume } \\
(\mathrm{ml})\end{array}$ & $\begin{array}{l}\text { Cell count } \\
\left(\times 10^{9} / l\right)\end{array}$ & $L T B_{4} t$ & 20-hydroxy-/carboxy-LTB ${ }_{4} t$ & $L T B_{4}$ isomert & \\
\hline $\begin{array}{r}1 \\
2 \\
3 \\
4 \\
5 \\
6 \\
7 \\
8 \\
9 \\
10 \\
11 \\
12 \\
13\end{array}$ & $\begin{array}{l}\text { Gout } \\
\text { Gout } \\
\text { Seronegative RA } \\
\text { Undiágnosed } \\
\text { Pseudogout } \\
\text { Gout } \\
\text { Gout } \\
\text { Seronegative RA } \\
\text { Seronegative RA } \\
\text { Seropositive RA } \\
\text { Sepsis } \\
\text { Pseudogout } \\
\text { Undiagnosed }\end{array}$ & $\begin{array}{r}25 \\
30 \\
27 \\
30 \\
12 \\
15 \\
3 \\
20 \\
50 \\
25 \\
30 \\
35 \\
20\end{array}$ & $\begin{array}{l}13 \cdot 30 \\
\text { NA } \\
48 \cdot 25 \\
0 \cdot 350 \\
112 \\
13 \cdot 65 \\
\text { NA } \\
0 \cdot 425 \\
14 \cdot 00 \\
11 \cdot 50 \\
32 \cdot 00 \\
11 \cdot 30 \\
\text { NA }\end{array}$ & $\begin{array}{c}1 \cdot 3 \\
1 \cdot 6 \\
9 \cdot 0 \\
8 \cdot 8 \\
2 \cdot 0 \\
28 \cdot 1 \\
0 \cdot 12\end{array}$ & $\begin{array}{l}0 \cdot 2 \\
0.01\end{array}$ & $\begin{array}{l}1.8 \\
2.4\end{array}$ & $\begin{array}{r}2 \cdot 3 \\
10 \cdot 0\end{array}$ \\
\hline
\end{tabular}

*NA = not available; $\mathrm{RA}=$ rheumatoid arthritis.

$+\mathrm{LTB}_{4}=$ leukotriene $\mathrm{B}_{4}$

†diHETE = dihydroxyeicosatetraenoic acid.

were used to calculate the amount of lipoxygenase products with conjugated diene and triene structures by measuring the area beneath the peak height at a given $\lambda_{\max }$. An absorption coefficient of $51000 \mathrm{~mol}^{-1} 1 \mathrm{~cm}^{-1}$ (at $270 \mathrm{~nm}$ )

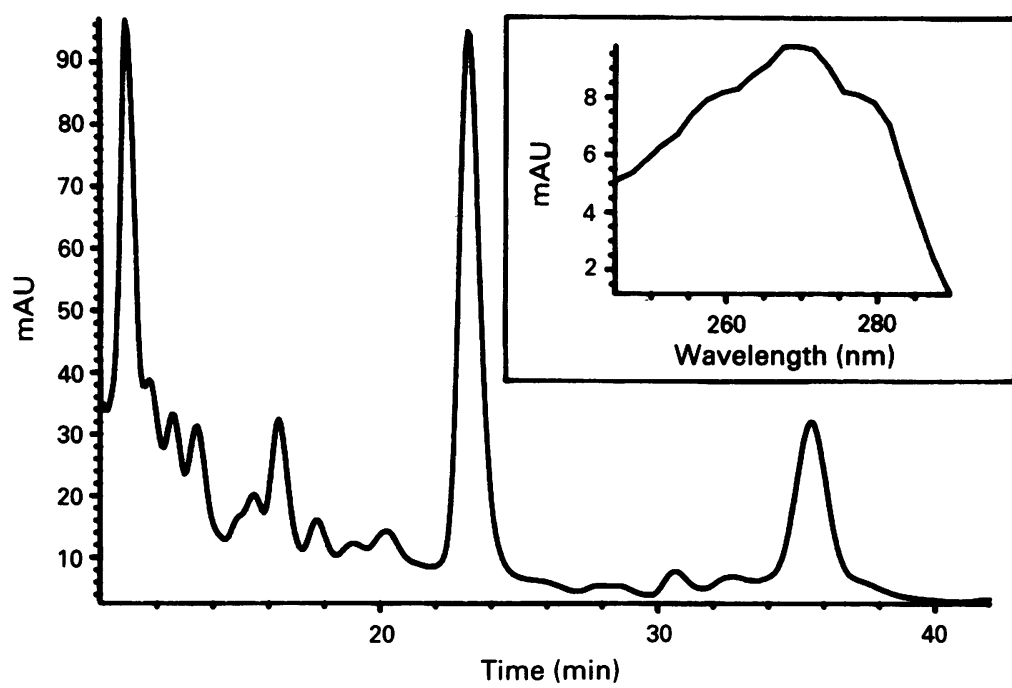

Figure 1 Reversed phase high performance liquid chromatograph of the extract of synovial fluid from patient 8 with seronegative rheumatoid arthritis. The HPLC run was monitored at a wavelength of $270 \mathrm{~nm}$. The peak at $35 \cdot 5$ minutes represents leukotriene $B_{4}$. The inset shows the ultraviolet spectrum for this peak with a $\lambda_{\max }$ of $270 \mathrm{~nm}$.

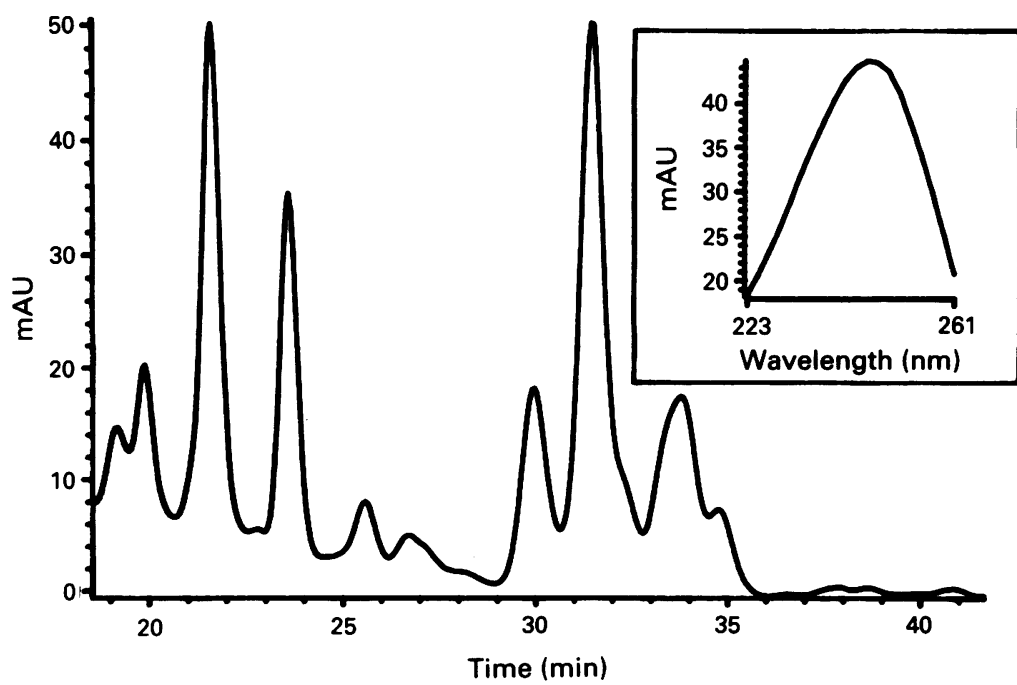

Figure 2 Reversed phase high performance liquid chromatogram of synovial fluid from patient 12 with pesudogout. The HPLC run was monitored at a wavelength of $245 \mathrm{~nm}$. The peak at 31.4 minutes has a retention time and ultraviolet spectrum (inset) consistent with 5,15-dihydroxyeicosatetraenoic acid. was used for leukotriene $B_{4}$, 20-hydroxy-leukotriene $B_{4}$, and 20-carboxy-leukotriene $B_{4}$ in these calculations. ${ }^{3}$ For approximate measurement of the unknown triene, the absorption coefficient and molecular mass of leukotriene $B_{4}$ were used with the assumption that these properties of the unknown triene compound were not considerably different from those of leukotriene $B_{4}$. The amount of product was corrected for the loss which occurred during extraction, as measured by the recovery of the internal standard. Cell counts were measured using a ZBI Coulter counter.

\section{Results}

Forty six synovial fluids were assayed for their total (intracellular and extracellular) concentration of specific diHETE lipoxygenase products. The system which was used allowed identification of leukotriene $B_{4}$, leukotriene $B_{4}$ isomers (6-trans and 6-trans, 12-epi-leukotriene $\mathrm{B}_{4}$ ), and the primary metabolites of leukotriene $B_{4}$ (20carboxy-leukotriene $B_{4}$ and 20-hydroxy-leukotriene $B_{4}$. 5,15-Dihydroxyeicosatetraenoic acid was also recognisable by its retention time and $\lambda_{\max }$ at $243 \mathrm{~nm}$.

Thirteen of 46 fluids (28\%) from 42 patients had one or more of these 5-lipoxygenase products (table 1 ) at the time of sampling. Leukotriene $B_{4}$ was present in seven synovial fluids in the concentration range $0 \cdot 1-28 \cdot 1 \mathrm{ng} / \mathrm{ml}$. Figure 1 shows the chromatogram of a joint fluid from a patient with a seronegative inflammatory disease in which leukotriene $\mathrm{B}_{4}$ elutes at 35.5 minutes. Low concentrations of 20hydroxy-leukotriene $\mathrm{B}_{4}$ or 20-carboxy-leukotriene $B_{4}$ metabolites were present in three samples, two of which also contained leukotriene $B_{4}$. Three synovial fluid samples contained trienes which comigrated with 6-trans or 6-trans, 12-epileukotriene $B_{4}$. None of these three contained leukotriene $B_{4}$. Four additional fluids were found to contain 5,15-diHETE in concentrations ranging from $2 \cdot 3$ to $16 \cdot 4 \mathrm{ng} / \mathrm{ml}$. Figure 2 is a chromatogram of an effusion from a patient with pseudogout. In this sample, a peak at 31.4 minutes had an ultraviolet spectrum with a $\lambda_{\max }$ at $243 \mathrm{~nm}$, which was consistent with 5,15 diHETE

The presence or absence of these 5-lipoxygenase products was not considerably different 
Table 2 Lipoxygenase products in septic peritoneal and pleural fluids

\begin{tabular}{|c|c|c|c|c|c|}
\hline Exudate & $\begin{array}{l}\text { Volume } \\
(m l)\end{array}$ & $L T B_{4}^{*}$ & $\begin{array}{l}\text { 20-carboxy-LTB }{ }_{4}^{*} \\
(n g / m l)\end{array}$ & $\begin{array}{l}\text { 6-trans-LTB }{ }_{+}^{*} \\
(n g / m l)\end{array}$ & $\begin{array}{l}\text { 6-trans-12-epi-LTB }{ }_{4}^{*} \\
(\mathrm{ng} / \mathrm{ml})\end{array}$ \\
\hline $\begin{array}{l}\text { Peritoneal } \\
\text { Cells } \\
\text { Supernatant }\end{array}$ & $\begin{array}{r}5 \\
100\end{array}$ & $\begin{array}{l}5 \cdot 2 \\
0.33\end{array}$ & $\begin{array}{l}9 \cdot 8 \\
7 \cdot 0\end{array}$ & $\begin{array}{l}\text { ND } \\
0 \cdot 11\end{array}$ & $\begin{array}{l}\text { ND } \\
1 \cdot 1\end{array}$ \\
\hline $\begin{array}{l}\text { Pleural } \\
\text { Cells } \\
\text { Supernatant }\end{array}$ & 20 & $\begin{array}{l}1.4 \\
0.54\end{array}$ & $\begin{array}{l}\text { Trace } \\
0 \cdot 19\end{array}$ & $\begin{array}{l}1.0 \\
0.53\end{array}$ & $\begin{array}{l}1 \cdot 1 \\
0.94\end{array}$ \\
\hline
\end{tabular}

$\mathrm{ND}=$ not detected.

${ }^{*} \mathrm{LTB}_{\mathbf{4}}=$ leukotriene $\mathrm{B}_{4}$.

in the various inflammatory joint diseases. There was no correlation between the total white blood cell counts and 5-lipoxygenase activation. For example, one septic/gouty effusion (white blood cell count about $200 \times 10^{9} / 1$ ) was serially assayed for 5-lipoxygenase products and these were not found.

Several synovial fluid samples were noted to have spectra which were similar in shape to those of leukotriene $B_{4}$ but which did not have

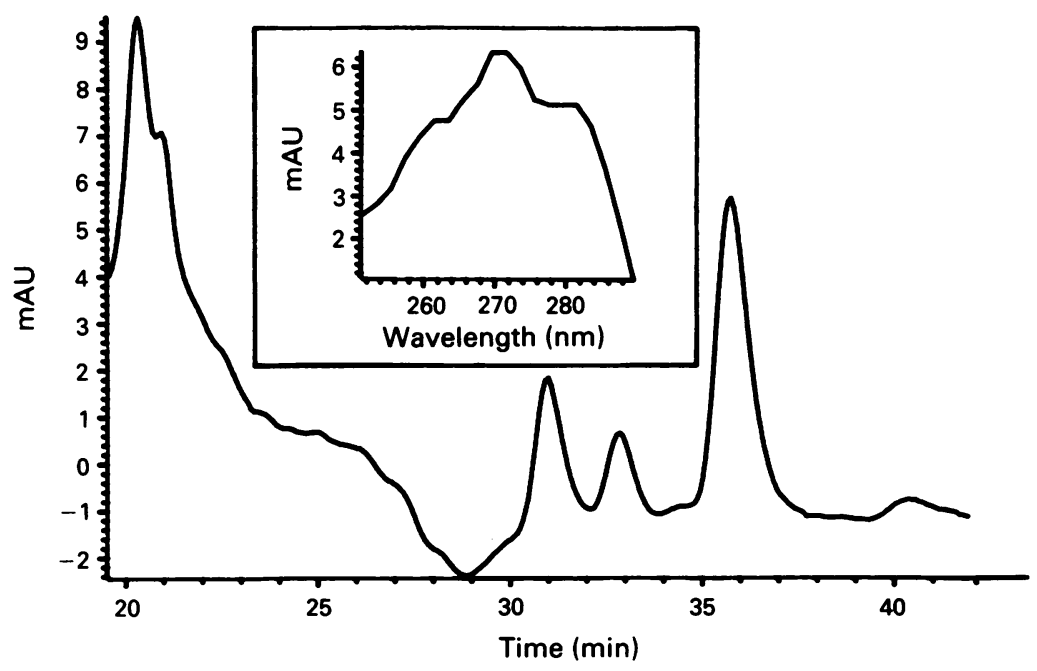

Figure 3 Reversed phase high performance liquid chromatogram of septic peritoneal fluid. The HPLC run was monitored at a wavelength of $270 \mathrm{~nm}$. The peaks at 31,33 , and $35 \cdot 5$ minutes comigrated with 6-trans-leukotriene $B_{4}$, 6-trans, 12-epi-leukotriene $B_{4}$, and leukotriene $B_{4}$ respectively. The ultraviolet spectrum of the peak at 35.5 minutes (inset) is consistent with leukotriene $B_{4}$.

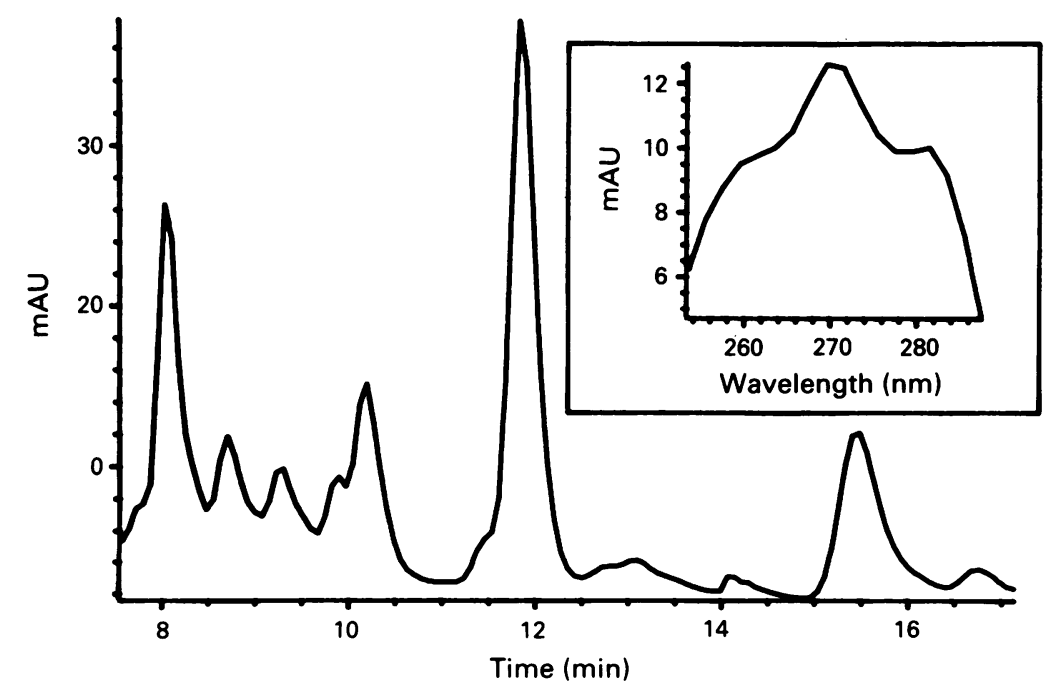

Figure 4 Rechromatograph, using a different mobile phase (see under Materials and Methods) of the seven to 10 minutes fraction collected during the chromatographic run shown in fig 3. The HPLC run was monitored at a wavelength of $270 \mathrm{~nm}$. In this mobile in $\mathrm{fg} 3$. The HPLC run was monitored at a wavelength of $270 \mathrm{~nm}$. In this mobile
phase the authenic 20 -carboxy-leukotriene $B_{4}$ standard elutes at 15 minutes. The ultraviolet spectrum of the peak at 15 minutes (inset) has a triene morphology and a $\lambda_{\text {max }}$ of $270 \mathrm{~nm}$, consistent with 20-carboxy-leukotriene $B_{+}$. elution times or a $\lambda_{\max }$ of known triene compounds. These 'unknown trienes' were present in five fluids in which they had retention times of 11-18 minutes and a $\lambda_{\max }$ of 280-284 nm; in two fluids they had a retention time of 11-12 minutes and a $\lambda_{\max }$ of $287-288 \mathrm{~nm}$; and in 10 fluids they had a retention time of $34-42$ minutes and a $\lambda_{\max }$ of $265 \mathrm{~nm}$. The latter unknown triene was present in relatively large concentrations in some samples (up to $29 \mathrm{ng} / \mathrm{ml}$ ).

5-Lipoxygenase products were also measured in several peritoneal cavity exudates. In four samples from chronic peritoneal dialysates complicated by staphylococcal peritonitis, no 5-lipoxygenase products were found. In one patient with septic peritonitis secondary to a ruptured bowel $100 \mathrm{ml}$ of purulent $\left(>100 \times 10^{9} / 1\right.$ white blood cells) peritoneal fluid was studied. A $35 \mathrm{ml}$ sample of septic pleural fluid was also studied. In these samples the cells and supernatant were assessed separately (table 2 ). These infected fluids contained leukotrienes in a concentration range similar to that seen in the joint fluid samples. Figure 3 shows a chromatogram from the supernatant of the peritoneal fluid with 6-trans-leukotriene $\mathrm{B}_{4}, 6$-trans, 12-epi-leukotriene $B_{4}$, and leukotriene $B_{4}$ eluting at 31,33 , and 35.5 minutes, respectively. Figure 4 shows the rechromatogram, using a different mobile phase, of the seven to 10 minutes fraction collected from the run shown in figure 3 , in which the 20-carboxy-leukotriene $B_{4}$ metabolite elutes at 15 minutes.

\section{Discussion}

The relative role of lipids with respect to other mediators in the inflammation of synovial and serous cavities is not known. It is possible that there may be differences in this role with respect to aetiology, time course, and even genetic factors. The first step might be to examine different inflammatory fluids for the presence of these mediators or their metabolic products in concentrations which would be compatible with a pathological role. We have therefore studied 5-lipoxygenase product generation in a variety of inflammatory joint disorders. Leukotriene $B_{4}$ or its isomers or metabolites or 5,15-diHETE (or both) was present in $28 \%$ of the samples tested. 5,15Dihydroxyeicosatetraenoic acid has not previously been reported in inflamed joint tissue. The cellular source of the 5,15-diHETE is not known. Transcellular metabolism could be part of the process. ${ }^{4}$

In our studies almost $50 \%$ of the fluids from patients with crystal induced arthritis contained 5-lipoxygenase products. Rae et al first reported 
increased levels of leukotriene $B_{4}$ in gouty synovial fluids measured by a bioassay. ${ }^{5}$ It has also been shown that peripheral neutrophils can be stimulated to produce leukotrienes by monosodium urate in vitro. Eicosanoids other than leukotriene $B_{4}$ were thought to be important inflammatory mediators in urate induced arthritis in dogs. ${ }^{6}$

We assayed 12 synovial fluids from patients with seropositive rheumatoid arthritis. Only one sample contained measurable concentrations of leukotriene $B_{4}$. Other workers have reported the presence of leukotriene $B_{4}$ in rheumatoid effusions, with concentrations varying greatly depending on the technique used. ${ }^{78}$ Klickstein et al reported levels of 5,12-diHETE (leukotriene $\left.B_{4}\right)$ in inflammatory and non-inflammatory joint fluid supernatants in the range $20-500 \mathrm{ng} / \mathrm{ml}^{7}$ In their studies leukotriene $\mathrm{B}_{4}$ was identified only by HPLC retention times. ${ }^{7}$ Davidson et al studied rheumatoid effusions by HPLC and a bioassay technique and detected leukotriene $B_{4}$ in a concentration range similar to that seen in this analysis. ${ }^{8}$ Biologically active leukotriene $B_{4}$ has also been measured in low nanogram concentrations in knee fluids from dogs with carageenan induced arthritis. ${ }^{9}$

The finding of these eicosanoids in inflamed tissue may depend on processes which are difficult to control experimentally. For example, it has been shown that leukotriene $B_{4}$ production in antigen induced arthritis in rabbits is significantly increased only in the early phase of the lesion. ${ }^{10}$ If leukotrienes are not uniformly produced during the course of human disease, then determining them in samples taken at a single time point may be misleading. The rate of metabolism of synthetic leukotriene $B_{4}$ was higher in synovial fluids from patients with rheumatoid arthritis compared with osteoarthritic controls. ${ }^{11}$ If leukotriene $B_{4}$ was rapidly metabolised to metabolites which had lost the triene chromophore, these would not be detectable by the HPLC technique used in these studies. In the patient with sepsis, the question could be raised as to whether the fact that leukotriene chemotactic factors were not formed and released early in the disease course could in some patients militates against successful phagocytosis and killing of the organism. The importance of 5-lipoxygenase products as chemotactic factors responsible for leucocyte attraction in bacterial infection has not been carefully studied in human disease or mammalian models. In a frog model of septic peritonitis in vivo 5-lipoxygenase products were routinely found early after an injection of the organism. ${ }^{12}$ The pattern of eicosanoids found was related to the species of the frog and not to the species of organism.

In the limited studies performed on septic fluids outside the joint the extracellular and intracellular concentrations (but not total amounts) of eicosanoids were similar. This indicates that the inflammatory cells had lost their barrier function for these products. As the inflammatory fluids by definition contain a high albumin concentration it is possible that the eicosanoids released were largely protein bound. In vivo animal studies, however, have shown some potent biological effects of these agentsthat is, chemotaxis in the presence of normal serum proteins. The metabolism of leukotriene $B_{4}$ to 20-carboxy-leukotriene $B_{4}$ almost certainly took place in the neutrophils. This implies that the production of leukotriene $B_{4}$ took place not as an agonal event in the life of the neutrophil, ${ }^{13}$ but that the mitochondrial enzymes were intact at the time of leukotriene synthesis. This may suggest a pathophysiological role. The poor correlation between numbers of inflammatory cells and concentrations of leukotrienes suggests that other specific or selective factors which have yet to be identified may be responsible for their presence.

Supported by the Veterans Administration, the Western New York Chapter of the Arthritis Foundation, and NIH Grant HL 24009.

1 Samuelsson B, Dahlén S-E, Lindgren J, et al. Leukotrienes and lipoxins: Structures, biosynthesis and biological effects. Science 1987; 237: 1171-6.

2 Higgs G A. In: Piper P, ed. The Leukotrienes: their biological significance. New York: Raven Press, 1986: 135-40.

3 Borgeat P, Samuelsson B. Metabolism of arachidonic acid in polymorphonuclear leukocytes. Structural analysis of novel
hydroxylated compounds. $₹$ Biol Chem 1979; 254: 7865-9.

4 Marcus A J. Transcellular metabolism of eicosanoids. Prog Haemost Thromb 1986; 8: 127-42.

5 Rae S A, Davidson E M, Smith M J H. Leukotriene $B_{4}$, an inflammatory mediator in gout. Lancet 1982; ii: 1122-4.

6 Carlson R P, Chang J, Datko L J, et al. Questionable role of leukotriene $\mathrm{B}_{4}$ in monosodium urate (MSU)-induced synovitis in the dog. Prostaglandins 1986; 32: 579-85.

7 Klickstein L B, Shapleigh C, Goetzl E J. Lipoxygenation of arachidonic acid as a source of polymorphonuclear leukocyte chemotactic factors in synovial fluid and tissue in rheumatoid arthritis and spondyloarthritis. F Clin Invest 1980; 66: 1166-70.

8 Davidson E M, Rae S A, Smith M J H. Leukotriene $B_{4}$, a mediator of inflammation present in synovial fluid in mediator of inflammation present in synovial fluid

9 Herlin T, Foch K, Ewald H, et al. Changes in lipoxygenase products from synovial fluid in carrageenan induced products from synovial fluid in carrageen
arthritis in dogs. APMIS 1988; $96: 601-4$.

10 Henderson B, Higgs G A. Synthesis of arachidonate oxidation products by synovial joint tissues during the development of chronic erosive arthritis. Arthritis Rheum 1987; 30: 1149-56.

11 Forrest $M$ J, Burton D, Brooks P M. The metabolism of synthetic leukotriene $\mathbf{B}_{4}$ in synovial fluid and whole human blood. Prostaglandins 1987; 34: 433-43.

12 Green F A. In vivo generation of 5-lipoxygenase products in frogs and toads. Biochem Biophys Res Commun 1987; 148: 1533-9.

13 Green F A. Leukotriene production associated with leukocyte membrane destruction. Inflammation 1988; 12: 133-40. 